\title{
Conditional knock out of transcription factor CTCF in excitatory neurons induces cognitive deficiency
}

\author{
Dong II Choi ${ }^{1}$, Myeongwon Kim¹, Somi Kim', Nam-Kyung Yu', Chuljung Kwak', Hyunhyo Seo², Kyungmin Lee \\ and Bong-Kiun Kaang ${ }^{1 *}$ (D)
}

\begin{abstract}
CCCTC-binding factor (CTCF) is a transcription factor that is involved in organizing chromatin structure. A reduction of CTCF expression is known to develop distinct clinical features. Furthermore, conditional knock out (cKO) study revealed reactive gliosis of astrocytes and microglia followed by age-dependent cell death in the excitatory neurons of CTCF CKO mice. To assess the cognitive ability in CTCF CKO mice of over 20 weeks of age, we examined pairwise discrimination (PD), PD reversal learning (PDr), and different paired-associate learning (dPAL) tasks using a touch screen apparatus. We found cognitive impairment in dPAL touch screen tests, suggesting that prolonged Ctcf gene deficiency results in cognitive deficits.
\end{abstract}

CTCF is a highly conserved zinc finger nuclear protein [1], acting as a genome organizer and a transcription factor. It is multifunctional organizer involved in chromatin remodeling by binding to nuclear genome through its zinc finger motifs to recruit other transcriptional regulators, to insulate the promoters and enhancers in the genome [1,2]. Given this critical genome-wide function, CTCF knockout mice are embryonic lethal. Therefore, conditional knockout approaches have been used to examine its role in the brain [3-5]. We showed that $C t c f$ gene deficiency leads to altered gene expression and impaired synaptic plasticity in the forebrain of adult mice $[4,6]$. Moreover, recently we also showed neuroinflammation with reactive gliosis in the cortex from 16 weeks of age accompanied by neuronal cell death at

\footnotetext{
*Correspondence: irislkm@knu.ac.kr; kaang@snu.ac.kr

${ }^{1}$ School of Biological Sciences, College of Natural Sciences, Seoul

National University, 1 Gwanangno, Gwanak-gu, Seoul 08826, South Korea

${ }^{2}$ Laboratory for Behavioral Neural Circuitry and Physiology, Department

of Anatomy, Brain Science and Engineering Institute, School of Medicine, Kyungpook National University, 680 Gukchaebosang-ro, Jung-gu,

Daegu 41944, South Korea
}

over 20 weeks of age in forebrain glutamatergic neuronspecific Ctcf gene KO (CTCF cKO) mice [7].

CTCF cKO mice have been previously reported to exhibit impairments to hippocampus-dependent memory and cortex-dependent remote memory $[4,5]$. However, these studies were performed in relatively young CTCF cKO mice (10-20 weeks old). Given the neurodegeneration-like changes in the cortex of cKO mice, we wanted to examine cognitive impairment of prolonged Ctcf gene deficiency in animals $>20$ weeks old using a more complex behavioral paradigm by applying the mouse touch screen test [8]. As touch screen tests are also used for humans, they are relatively more complex and difficult than most mouse battery tests. Touch screen tests require weeks of pre-training before the actual test, hence providing reliable data on mouse learning skills and test results.

The touch screen-based behavioral experiments for pairwise discrimination (PD), PD reversal learning (PDr) and different paired-associate learning (dPAL) tasks were performed as described in our previous studies $[9,10]$ (Additional file 1). When mice fulfilled the original author(s) and the source, provide a link to the Creative Commons licence, and indicate if changes were made. The images or other third party material in this article are included in the article's Creative Commons licence, unless indicated otherwise in a credit line to the material. If material is not included in the article's Creative Commons licence and your intended use is not permitted by statutory regulation or exceeds the permitted use, you will need to obtain permission directly from the copyright holder. To view a copy of this licence, visit http://creativecommons.org/licenses/by/4.0/. The Creative Commons Public Domain Dedication waiver (http://creativeco mmons.org/publicdomain/zero/1.0/) applies to the data made available in this article, unless otherwise stated in a credit line to the data. 
success criteria (correct response $>80 \%$ ) in PD learning, we performed PD reversal learning by switching $\mathrm{S}+$ (reward giving stimulus) and $\mathrm{S}-$ (beep alert stimulus) to measure behavioral flexibility. We examined the learning performance over time in control and cKO mice for 10 days (Fig. 1a) with linear regression analysis (Fig. 1b). We found that the learning enhancement per day (\%) is significantly lower in cKO group during reversal leaning compared to control group (Fig. 1c; control $=7.4496 \pm 0.713 \% /$ day,$\quad c K O=3.3246 \pm 1.124 \%$ / day; $\mathrm{t}(11)=2.973$, " $p=0.012668$; independent $t$ test). These data suggest that the ability to suppress a previous reward-related response is decreased in $\mathrm{cKO}$, indicating a deficit of behavioral flexibility in cKO mice.

Furthermore, in the dPAL test, compared to the controls, CTCF cKO mice showed impairments in selecting the correct response. Although CTCF cKO and control mice started the training with a similar level of correct responses, CTCF cKO mice displayed a learning deficit as training proceeded and did not reach the same level

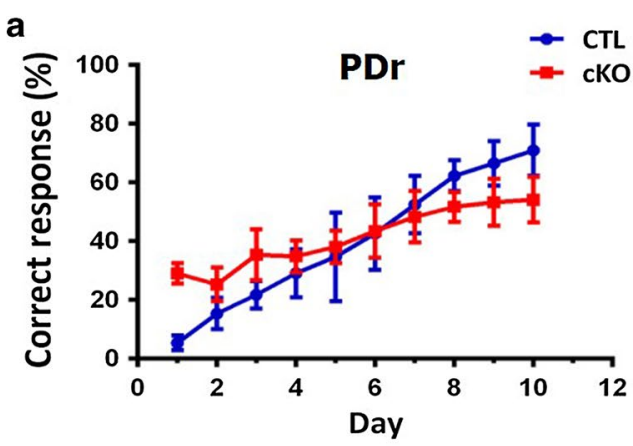

b
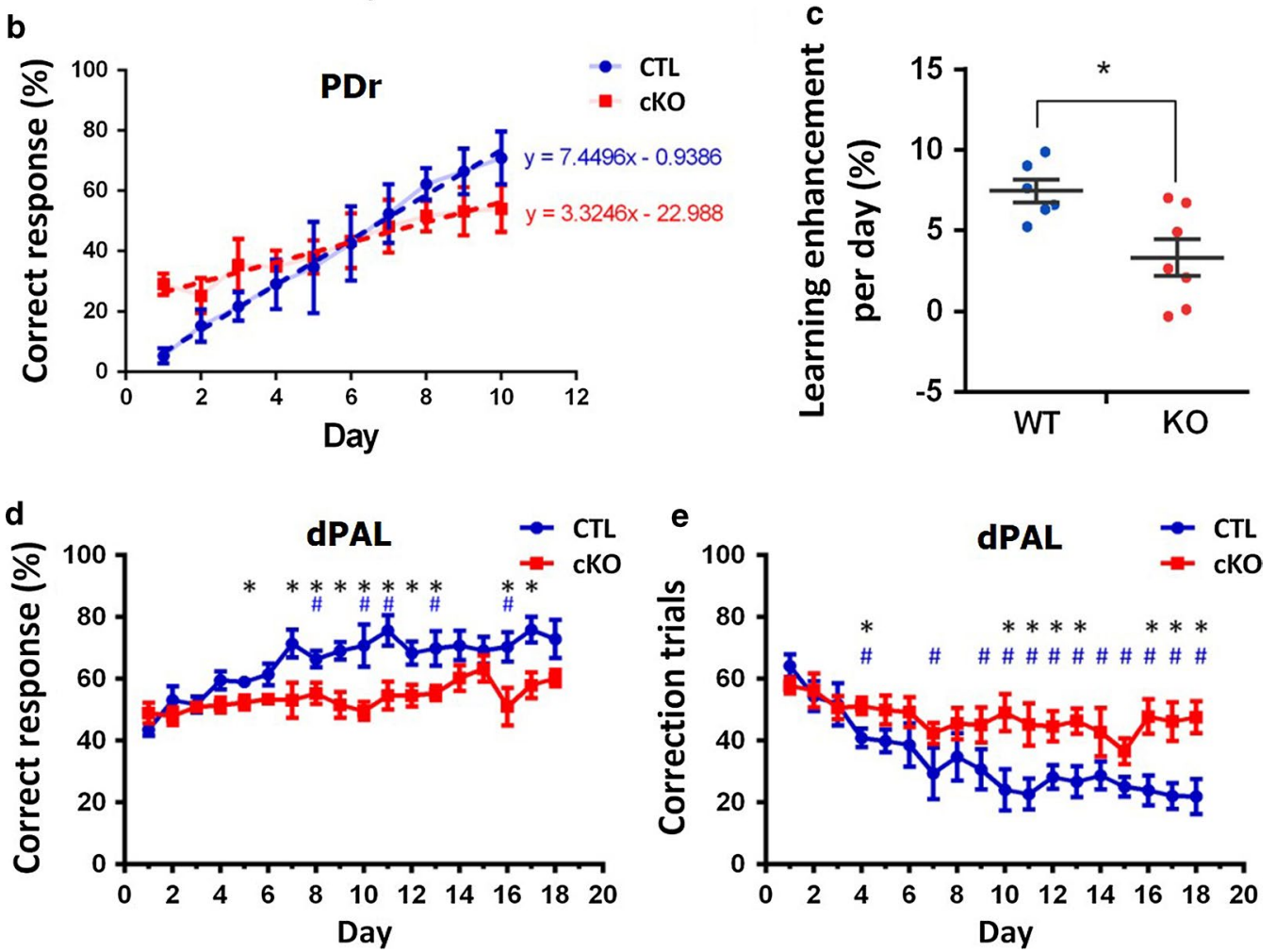

Fig. 1 Touch screen analysis of behavioral phenotypes showed cognitive impairments in CTCF CKO mice. a PD reversal accuracy (i.e., correct response) rate. $\mathbf{b}$ Linear regression between correct response rate and time in the PD reversal leaning. $\mathbf{c}$ Comparison of reversal learning rate per day (\%) between control and CKO mice. Individual dots represent data from individual animals. $\mathbf{d}$ Accuracy rate of different paired-associate learning (dPAL) touch screen test trials was measured after habituation and pre-training. In the dPAL test, adult CTCF CKO mice showed a moderate cognitive impairment. ${ }^{*} p<0.05,{ }^{*} p<0.05$. e Time course of learning phase during dPAL test. Note that the number of correction trial is decreased more rapidly in the controls than in $\mathrm{CKO}$ mice which showed no difference in the number of correction trial from day 1 to day $18 .{ }^{*} p<0.05,{ }^{*} p<0.05$ 
of correct responses as control mice (Fig. 1d). In the dPAL data analysis, we found a significant interaction between "genotype" and "time" (Fig. 1d; genotype: F(1, $11)=12.551, p=0.005$, time: $\mathrm{F}(9.809,107.898)=6.513$, $p=0.0000001$, interaction: $\mathrm{F}(9.809,107.898)=2.459$, $p=0.011$; two-way ANOVA with mixed design repeated measures). Simple main effect analysis as a post-hoc revealed that CTCF cKO mice showed impairments in selecting the correct response compared to the controls (Fig. $1 \mathrm{~d}$; for day 5 , $" p=0.037$; for day $7,{ }^{*} p=0.031$; for day $8, * p=0.030$; for day $9, " p=0.006$; for day $10, " p=0.013$, for day $11, * p=0.009$, for day $12, * p=0.021$, for day 13 , $" p=0.027$, for day $16, " p=0.034$, for day $17, " p=0.012$ ). Although CTCF cKO and control mice started the training with a similar level of correct responses at day 1 , CTCF cKO mice displayed a moderate learning deficit as training proceeded and did not reach the same level of correct responses compared with the control mice showing an enhancement of correct response over time (Fig. 1d; for day $8,{ }^{*} p=0.040$; for day $10,{ }^{*} p=0.035$; for day $11,{ }^{\#} p=0.033$; for day $13,{ }^{\#} p=0.037$; for day 16 ${ }^{\#} p=0.010$; simple main effect analysis with pairwise comparison). During the training periods, the number of correction trials was analyzed in CTCF cKO and control mice by two-way ANOVA with repeated measures and we found a significant interaction between "genotype" and "time" (mixed model ANOVA; Fig. 1e; genotype: $\mathrm{F}(1,11)=6.304, p=0.029$, time: $\mathrm{F}(9.814$, $107.950)=9.571, \quad p=0.000000000039$, interaction: $\mathrm{F}(9.814,107.950)=2.958, p=0.003)$. Then, simple main effect analysis as a post-hoc revealed that the control mice showed a significant decrease in the number of correction trials over time compared to cKO mice (Fig. 1e; for day $4, " p=0.027$; for day $10, " p=0.017$; for day 11 , $" p=0.026$; for day $12, " p=0.025$; for day $13, " p=0.011$, for day $16, " p=0.009$, for day $17, " p=0.010$, for day 18 , $" p=0.007)$. Moreover, when comparing the correction trial number of day 1 with each one of day 2 to day 18 , the number of correction trials decreased more rapidly in the controls than in cKO mice showing no difference over time (Fig. 1e; in control mice: for day $4,{ }^{\#} p=0.031$; for day $7,{ }^{*} p=0.031$; for day $9,{ }^{*} p=0.049$; for day $10,{ }^{*} p=0.005$; for day $11,{ }^{\#} p=0.003$; for day $12,{ }^{*} p=0.001$; for day 13 , ${ }^{\#} p=0.002$; for day $14,{ }^{*} p=0.045$; for day $15,{ }^{*} p=0.002$; for day $16,{ }^{*} p=0.003$; for day $17,{ }^{*} p=0.004$; for day 18 , ${ }^{\#} p=0.002$; simple main effect analysis with pairwise comparison).Taken together, these results indicate that CTCF cKO mice show a deficit in behavioral flexibility and cognitive function, which may be related to the cell death and reactive gliosis caused by CTCF deficiency.

In this study, we showed that adult CTCF CKO mice exhibited signs of lack of behavioral flexibility and cognitive dysfunction in the PDr and dPAL touch screen test. These cognitive impairments are likely due to the loss of glutamatergic neurons in the cortex, particularly in the ACC, as inhibitory neurons in the striatum are relatively intact in adult CTCF $\mathrm{CKO}$ mice [7]. ACC is known to be involved in behavioral flexibility as well as decision making, adaptation, and anticipation in rodents [11]. Therefore, it is possible that CTCF deficiency in the ACC may lead to lack of behavior flexibility in adult CTCF cKO mouse. Although CTCF deficiency has been demonstrated to be prominent in the ACC [7], which plays a critical role in remote memory formation [12, 13], pain processing [12], and other higher cognitive functions [14], other forebrain areas may also contribute to the cognitive dysfunction induced by CTCF deficiency. As we reported previously, the hippocampus plays a key role in dPAL leaning [9]. Interestingly, it was reported that direct glutamatergic projection from the ACC to hippocampal CA1 and CA3 region is involved in retrieval of contextual fear memory [15]. In this regard, loss of glutamatergic neurons in the ACC of CTCF cKO mice and the hippocampus may affect retrieval of association between location and visual stimuli during dPAL learning. Further, although 12-15-week old Ctcf $\mathrm{cKO}$ mice did not show any deficit in learning and recent memory storage during contextual fear conditioning and Morris water maze task [5], it is still possible that younger mice at earlier ages could show a deficit in our touch screen-based cognition test that remains to be resolved in the future.

\section{Supplementary Information}

The online version contains supplementary material available at https://doi. org/10.1186/s13041-020-00716-z.

Additional file 1. Supplementary materials \& methods.

\section{Acknowledgements}

Not applicable.

\section{Authors' contributions}

DIC, SK, N-KY, and B-KK designed the experiments. DIC, MWK, SK, N-KY, CK, HS, $\mathrm{KL}$ conducted and analyzed the experiments. DIC, CK, KL, and B-KK wrote the manuscript. All authors read and approved the final manuscript.

\section{Funding}

Supported by the National Research Foundation (NRF) through grants funded by the Korean government (MSIP) [NRF-2019R1F1A1063932] to K.L. and [NRF-2012R1A3A1050385] to B.K.K., and by L'Oreal Korea-UNESCO Women in Science fellowship and L'Oreal-UNESCO Rising Talent Award to N.K.Y.

\section{Availability of data and materials}

The data supporting the conclusions of this study are included in this article and Additional file 1. Additional data are available from the corresponding author upon request.

\section{Ethics approval and consent to participate}

The Animal Care and Use Committees of Seoul National University approved the animal protocols. 


\section{Consent for publication}

Not applicable.

\section{Competing interests}

The authors declare that they have no competing interests.

Received: 17 October 2020 Accepted: 14 December 2020

Published online: 05 January 2021

\section{References}

1. Kim S, Yu N-K, Kaang B-K. CTCF as a multifunctional protein in genome regulation and gene expression. Exp Mol Med. 2015;47:e166-e166.

2. Gaszner M, Felsenfeld G. Insulators: exploiting transcriptional and epigenetic mechanisms. Nat Rev Genet. 2006;7:703-13.

3. Hirayama T, Tarusawa E, Yoshimura Y, Galjart N, Yagi T. CTCF is required for neural development and stochastic expression of clustered Pcdh genes in neurons. Cell Rep. 2012;2:345-57.

4. Kim S, Yu N-K, Shim K-W, Kim J-I, Kim H, Han DH, Choi JE, Lee S-W, Cho DI, Kim MW. Remote memory and cortical synaptic plasticity require neuronal CCCTC-binding factor (CTCF). J Neurosci. 2018:38:5042-52.

5. McGill BE, Barve RA, Maloney SE, Strickland A, Rensing N, Wang PL, Wong M, Head R, Wozniak DF, Milbrandt J. Abnormal microglia and enhanced inflammation-related gene transcription in mice with conditional deletion of Ctcf in Camk2a-Cre-expressing neurons. J Neurosci. 2018;38:200-19.

6. Kim S, Kaang B-K. Epigenetic regulation and chromatin remodeling in learning and memory. Exp Mol Med. 2017;49:e281-e281.

7. Kwak JH, Kim S, Yu NK, Seo H, Choi JE, Kim Jl, Choi DI, Kim MW, Kwak C, Lee $\mathrm{K}$, Kaang BK. Loss of the neuronal genome organizer and transcription factor CTCF induces neuronal death and reactive gliosis in the anterior cingulate cortex. Genes Brain Behav. 2020:e12701. https://doi. org/10.1111/gbb.12701.
8. Kim CH, Heath CJ, Kent BA, Bussey TJ, Saksida LM. The role of the dorsal hippocampus in two versions of the touchscreen automated paired associates learning (PAL) task for mice. Psychopharmacology. 2015;232:3899-910

9. Kim M, Kwak C, Yu N-K, Kaang B-K. Optimization of the touchscreen paired-associate learning (PAL) task for mice and its dorsal hippocampal dependency. Animal Cells Syst. 2016;20:229-36.

10. Kim S, Kim T, Lee HR, Jang EH, Ryu HH, Kang M, Rah SY, Yoo J, Lee B, Kim $\mathrm{J}$, et al. Impaired learning and memory in CD38 null mutant mice. Mol Brain. 2016;9:16

11. Elston TW, Croy E, Bilkey DK. Communication between the anterior cingulate cortex and ventral tegmental area during a cost-benefit reversal task. Cell Rep. 2019;26(2353-2361):e2353.

12. Kang SJ, Kwak C, Lee J, Sim S-E, Shim J, Choi T, Collingridge GL, Zhuo M, Kaang B-K. Bidirectional modulation of hyperalgesia via the specific control of excitatory and inhibitory neuronal activity in the ACC. Mol Brain. 2015;8:81.

13. Lee J, Lee H-R, Kim J-I, Baek J, Jang E-H, Lee J, Kim M, Lee RU, Kim S, Park P. Transient CAMP elevation during systems consolidation enhances remote contextual fear memory. Neurobiol Learn Memory. 2020;169:107171.

14. Bliss TV, Collingridge GL, Kaang B-K, Zhuo M. Synaptic plasticity in the anterior cingulate cortex in acute and chronic pain. Nat Rev Neurosci. 2016;17:485.

15. Rajasethupathy P, Sankaran S, Marshel JH, Kim CK, Ferenczi E, Lee SY, Berndt A, Ramakrishnan C, Jaffe A, Lo M, et al. Projections from neocortex mediate top-down control of memory retrieval. Nature. 2015;526:653-9.

\section{Publisher's Note}

Springer Nature remains neutral with regard to jurisdictional claims in published maps and institutional affiliations.
Ready to submit your research? Choose BMC and benefit from:

- fast, convenient online submission

- thorough peer review by experienced researchers in your field

- rapid publication on acceptance

- support for research data, including large and complex data types

- gold Open Access which fosters wider collaboration and increased citations

- maximum visibility for your research: over $100 \mathrm{M}$ website views per year

At $\mathrm{BMC}$, research is always in progress.

Learn more biomedcentral.com/submissions 